\section{Padronização de condições para detecção de DNA de Leishmania spp. em flebotomíneos (Diptera, Psychodidae) pela reação em cadeia da polimerase}

\author{
Standardization of conditions for PCR detection \\ of Leishmania spp. DNA in sand flies (Diptera, \\ Psychodidae)
}

\footnotetext{
${ }^{1}$ Instituto de Medicina Tropical de São Paulo, Universidade de São Paulo, São Paulo, Brasil. 2 Instituto de Ciências Biomédicas, Universidade de São Paulo, São Paulo, Brasil. 3 Centro de Pesquisas René Rachou, Fundação Oswaldo Cruz, Belo Horizonte, Brasil. 4 Faculdade de Saúde Pública, Universidade de São Paulo, São Paulo, Brasil. 5 Faculdade de Medicina Universidade de São Paulo, São Paulo, Brasil.

Correspondência B. R. Paiva

Laboratório de Protozoologia Instituto de Medicina Tropical de São Paulo, Universidade de São Paulo. Av. Dr. Enéas Carvalho de Aguiar 470, São Paulo, SP 05403-000, Brasil. byapaiva@usp.br
}

\begin{abstract}
The correct identification of etiological agents in vector insects is crucial for epidemiological studies. Identification of flagellates in such vectors, usually by dissection of the digestive tract and microscopic observation of the contents as well as attempts at parasite isolation from insects in culture media, have proven operationally inadequate and with poor diagnostic specificity, since female sand flies are also hosts for other flagellates like Trypanosoma and Endotrypanum. Due to the efficiency and specificity of DNA target sequence amplification by polymerase chain reaction (PCR), the latter could be used to investigate the presence of Leishmania in sand flies, although the insects need to be properly stored and the Leishmania DNA extracted using appropriate methodology. This paper describes methodologies to standardize sand fly storage and Leishmania DNA extraction in such specimens as a more practical method in field studies.
\end{abstract}

Psychodidae; Leishmania; Polymerase Chain Reaction
Byanca Regina de Paiva 1,2

Nagilá Francinete Costa Secundino ${ }^{3}$

Paulo Fillemon Paulocci Pimenta ${ }^{3}$

Eunice Aparecida Biacnhi Galati 4

Heitor Franco Andrade Junior 1,2

Rosely dos Santos Malafronte 1,5

\section{Introdução}

As leishmanioses, protozooses heteroxênicas, apresentam alta prevalência em regiões tropicais como o Brasil, e seus agentes etiológicos, várias espécies do gênero Leishmania causam, geralmente, doença espectral tegumentar ou visceral 1 . Seus vetores compreendem insetos hematófagos, conhecidos como flebotomíneos ${ }^{2}$. As leishmânias apesar de apresentarem distribuição diferencial ao longo do tubo digestivo nos vetores, assumem forma flagelada indistinguível entre as espécies ${ }^{3}$. A pesquisa de flagelados no tubo digestivo do vetor e a identificação da espécie do parasita, normalmente são realizadas por observação microscópica após dissecção ${ }^{4}$ ou tentativa de isolamento do agente proveniente de insetos em meios de cultura. Porém, fêmeas de flebotomíneos também são hospedeiras de algumas espécies de Trypanosoma e Endotrypanum, que passam por um estágio de promastigota indistinguível das leishmânias 5 , complicando, sobremaneira, o diagnóstico microscópico e o isolamento em cultura ${ }^{6}$. Atualmente, o uso de técnicas moleculares, como a reação em cadeia da polimerase (PCR), tem aumentado a sensibilidade e especificidade da identificação do parasita ?

O objetivo do presente estudo foi padronizar métodos de conservação dos vetores e extração de DNA do parasita existente nestes, bem como avaliar o uso da técnica de PCR na detecção de Leishmania em flebotomíneos. A sensibilidade 
desses procedimentos foi testada com a utilização de iniciadores complementares a seqüências conservadas de DNA ribossômico ${ }^{8}$.

\section{Materiais e métodos}

Parasitas e vetores

As linhagens representativas das diferentes espécies de Leishmania utilizadas neste estudo foram: Leishmania (Viannia) braziliensis (MHOM/ BR/1975/M2903), Leishmania (Leishmania) amazonensis (IFLA/BR/67/PH8) e Leishmania (Leishmania) chagasi (MHOM/BR/1974/PP75(M2682).

As cepas foram mantidas em nitrogênio líquido ou em cultivo em meio M199 suplementado com hemina, gentamicina, soro fetal bovino $10 \%$ e urina masculina a $2 \%$. As formas amastigotas foram obtidas por transformação in vivo em hamster ou camundongo.

A nomenclatura adotada para a identificação dos flebotomíneos segue Galati 9. As seguintes espécies de flebotomíneos foram utilizadas: Lutzomyia longipalpis ( $\mathrm{n}=190)$, Lutzomyia almerioi ( $\mathrm{n}=04)$ e Nyssomyia intermedia $(\mathrm{n}=26)$, obtidas de colônias mantidas no Laboratório de Entomologia da Faculdade de Saúde Pública, Universidade de São Paulo (USP) e Laboratório de Entomologia Médica, Centro de Pesquisas René Rachou, Fundação Oswaldo Cruz (FIOCRUZ).

\section{Animais experimentais}

Os procedimentos utilizando-se animais foram aprovados pela Comissão de Ética do Instituto de Medicina Tropical de São Paulo da USP e pela Comissão de Ética em experimentação animal do Instituto de Ciências Biomédicas da USP.

\section{Infecção experimental de flebotomíneos}

\section{- Alimentados em animais}

Para a infecção experimental, camundongos e hamsters infectados respectivamente com $L$. (L.) amazonensis ou $L$. (L.) chagasi, comprovadamente, foram anestesiados, mantidos restritos e expostos às fêmeas, previamente em jejum, das espécies $L u$. almerioi e $N$. intermedia na ocasião de seu repasto sanguíneo. Esse procedimento foi realizado na Faculdade de Saúde Pública da USP.

\section{- Alimentação artificial de flebotomíneos}

A alimentação artificial foi realizada no Centro de Pesquisas René Rachou da FIOCRUZ, em Belo Horizonte, Minas Gerais. Todas as fêmeas pertenciam à espécie $\mathrm{Lu}$. longipalpis e foram alimentadas com formas promastigotas de $L$. (V.) braziliensis. Os alimentadores artificiais (mamadeiras) foram acoplados à pele de pinto, segundo o método descrito por Tesh \& Modi 10 .

Para a confirmação da infecção, $7 \%$ dos insetos foram dissecados e todos foram processados entre o terceiro e quarto dias pós-alimentação.

\section{Conservação dos flebotomíneos}

Os flebotomíneos utilizados neste estudo foram armazenados em tubos do tipo eppendorf sob duas formas: secos e conservados a $4^{\circ} \mathrm{C}$ ou imersos em isopropanol.

Todos os flebotomíneos obtidos da infecção experimental em animais e a maioria dos obtidos na infecção artificial foram conservados secos, a $4^{\circ} \mathrm{C}$, conforme protocolos existentes na literatura. Vinte flebotomíneos obtidos da infecção artificial foram conservados em isopropanol. A fim de se evitar a evaporação e conseqüente má conservação dos espécimes, volumes variando de 800 a $1.000 \mu l$ de isopropanol foram utilizados.

\section{Testes preliminares com insetos}

Como os insetos possuem quitina em seu exoesqueleto, resolveu-se avaliar a influência desta na detecção da infecção de parasitas, pela utilização da técnica de PCR. Para tanto, utilizou-se insetos íntegros ou apenas seu tubo digestivo.

Para a obtenção do tubo digestivo, flebotomíneos secos foram rehidratados com glicerol a $5 \%$ em água ( $50 \mu \mathrm{l} /$ inseto) por uma hora, em tubo cônico $(0,5 \mathrm{ml})$, previamente perfurado com agulha 25 , com ocasional agitação. O tubo foi adaptado a outro tubo $(1,5 \mathrm{ml})$, não perfurado e o conjunto centrifugado a $15.000 \mathrm{rpm}$ por 2 minutos, para que o conteúdo do inseto fosse transferido para o segundo tubo, ficando o exoesqueleto de quitina retido no primeiro tubo.

\section{Extração de DNA de flebotomíneos}

As extrações foram realizadas individualmente ou em "pools" de 2 a 12 flebotomíneos por tubo.

Dois protocolos para a extração de DNA foram testados. No primeiro, realizamos a extração "clássica" de ácidos nucléicos segundo metodologia preconizada por Michalsky et al. ${ }^{6}$. Os insetos foram macerados com o auxílio de um homogeneizador em $35 \mu$ de tampão de lise/inseto (100mM Tris-HCl, $100 \mathrm{Mm} \mathrm{NaCl,} \mathrm{25mM} \mathrm{EDTA} \mathrm{e}$ $0,5 \%$ SDS, pH 8,0). Após a adição de $1,25 \mu \mathrm{l} /$ inseto de proteinase $\mathrm{K}(10 \mathrm{mg} / \mathrm{ml})$, estes foram incubados "overnight" a $37^{\circ} \mathrm{C}$. No dia seguinte, o DNA foi extraído com a adição de fenol/clorofórmio/ 
álcool isoamílico (25:24:1) e precipitado com a adição de 0,1 volume de acetato de sódio (3M, pH $5,2)$ e 2 volumes de etanol absoluto gelado. Este foi levado ao freezer a $-20^{\circ} \mathrm{C}$ "overnight". No dia seguinte, a amostra foi centrifugada a $4^{\circ} \mathrm{C}$ por 10 minutos a 12.000rpm e o precipitado lavado com etanol 70\%. Após secagem, o DNA foi ressuspendido em $20 \mu \mathrm{l}$ de $\mathrm{H}_{2} \mathrm{O}$ destilada.

A extração do DNA dos flebotomíneos também foi testada pelo método preconizado por Oskam et al. 11 (1996) com pequenas modificações. Após a maceração dos insetos em $20 \mu \mathrm{l}$ tampão de lise (50mM NaCl, 10mM EDTA, pH 8,0, 50mM Tris-HCL pH 7,4, Triton X100 1\% e 10mM DTT) seguiram-se 3 ciclos de congelamento (nitrogênio liquido) e descongelamento $\left(60^{\circ} \mathrm{C}\right)$. Esse macerado foi incubado por 1 hora a $60^{\circ} \mathrm{C}$ e por mais 3 horas a $60^{\circ} \mathrm{C}$ com a adição de $1 \mu$ proteinase K $(20 \mathrm{mg} / \mathrm{ml})$, $80 \mu \mathrm{l}$ de tampão de lise e $1 \%$ de Triton X100 por inseto. Após a incubação, a amostra foi centrifugada por 10 minutos a 12.000rpm e ao sobrenadante recolhido foi acrescido 0,1 volume de acetato de sódio (3M, pH 5.2), 2 volumes de etanol absoluto gelado e este foi mantido "overnight" a $-20^{\circ} \mathrm{C}$. O material foi centrifugado a $4^{\circ} \mathrm{C}$ novamente por 10 minutos a $12.000 \mathrm{rpm}$, o precipitado lavado com etanol $70 \%$, e depois de seco, ressuspendido em $20 \mu \mathrm{l}$ de $\mathrm{H}_{2} \mathrm{O}$ destilada.

Avaliação dos protocolos de extração e inibição da técnica de PCR

Avaliamos, para ambos os protocolos, as possíveis perdas de DNA durante o processo de extração. Para tanto, foram acrescentadas aproximadamente 10, 20 e 40 leishmânias aos conteúdos intestinais e aos flebotomíneos inteiros $(L u$. longipalpis).

Para verificar a existência de possíveis componentes inibidores do PCR na identificação do parasita dentro do vetor, foram adicionados $10^{6}$ leishmânias a um "pool" de 10 flebotomíneos e DNA de 100 e 50 leishmânias ao DNA de 1 flebotomíneo.

\section{Iniciadores}

Para a avaliação da armazenagem e dos protocolos de extração de DNA foram utilizados os oligonucleotídeos S4 e S12, sendo a reação realizada em volume final de $25 \mu \mathrm{l}$, contendo $5 \mu \mathrm{l}$ de DNA, $2,5 \mu$ de tampão de reação $10 \mathrm{X}(50 \mathrm{mM} \mathrm{KCl}, 10 \mathrm{mM}$ Tris- $\mathrm{HCl} \mathrm{pH}$ 8,3), 1.5mM MgCl2, 0,25 $\mu \mathrm{M}$ de oligonucleotídeos , 200 $\mu \mathrm{M}$ de cada dNTP e 1.5U de Taq polimerase. O DNA foi desnaturado em $94^{\circ} \mathrm{C}$ por 3 minutos e amplificado com 35 ciclos nas seguintes condições: $94^{\circ} \mathrm{C}, 50^{\circ} \mathrm{C}$ e $72^{\circ} \mathrm{C} 1$ minuto cada e extensão final de $72^{\circ} \mathrm{C}$ por 7 minutos, amplificando um fragmento de 540 pares de base (pb) correspondendo a Leishmania spp., método preconizado por Uliana et al. ${ }^{8}$. Sendo assim, independentemente da espécie, a presença da Leishmania é assegurada, evitando falsos negativos.

O produto amplificado foi analisado por eletroforese em gel de poliacrilamida a $6 \%(120 \mathrm{~V}$ por 35 minutos), corado em solução de nitrato de prata a $0,2 \%$ e por gel de agarose a $1,5 \%(90 \mathrm{~V}$ por 60 minutos) corado com brometo de etídeo $(0,5 \mu \mathrm{g} / \mathrm{ml})$. Foram utilizados padrões de peso molecular de 100pb e 50pb (Invitrogen). Os fragmentos do gel de poliacrilamida foram observados diretamente pós-coloração e o gel de agarose sob luz ultravioleta e analisado pelo sistema de captura Labworks.

\section{Taxa mínima de infecção}

Por estarem em sua maioria acondicionados em pool, calculamos a taxa mínima de infecção dos flebotomíneos, adotando para tanto, a seguinte fórmula: taxa mínima (TM) = número de grupos positivos x 100/número total de insetos.

\section{Resultados}

\section{Conservação e extração de DNA de insetos}

Os dois métodos de conservação, secos a $4^{\circ} \mathrm{C}$ ou em isopropanol à temperatura ambiente mostraram-se adequados na preservação do material.

A Figura 1 mostra que a extração de DNA, utilizando o inseto inteiro, apresentou melhores resultados do que aquela, a partir de seu tubo digestivo.

Dos protocolos de extração de DNA, o método que incluiu passagens em fenol/clorofórmio/ álcool isoamílico demonstrou perda de sensibilidade na amplificação, gerando bandas inespecíficas. Já o DNA extraído com DTT/Triton X100, apresentou-se em melhores condições para amplificação (Figura 1).

\section{Detecção de leishmânias em insetos por PCR}

Após resultados iniciais, os espécimes abaixo foram utilizados inteiros e o DNA extraído pela metodologia de DTT-Triton X100.

\section{Alimentados experimentalmente em animais}

Trinta fêmeas alimentaram-se in vivo no hamster infectado com $L$. (L.) amazonensis, sendo $4 \mathrm{Lu}$. 
Amplificações do teste de extração de DNA em Lutzomyia longipalpis (Triton/DTT) com iniciadores S4/S12.

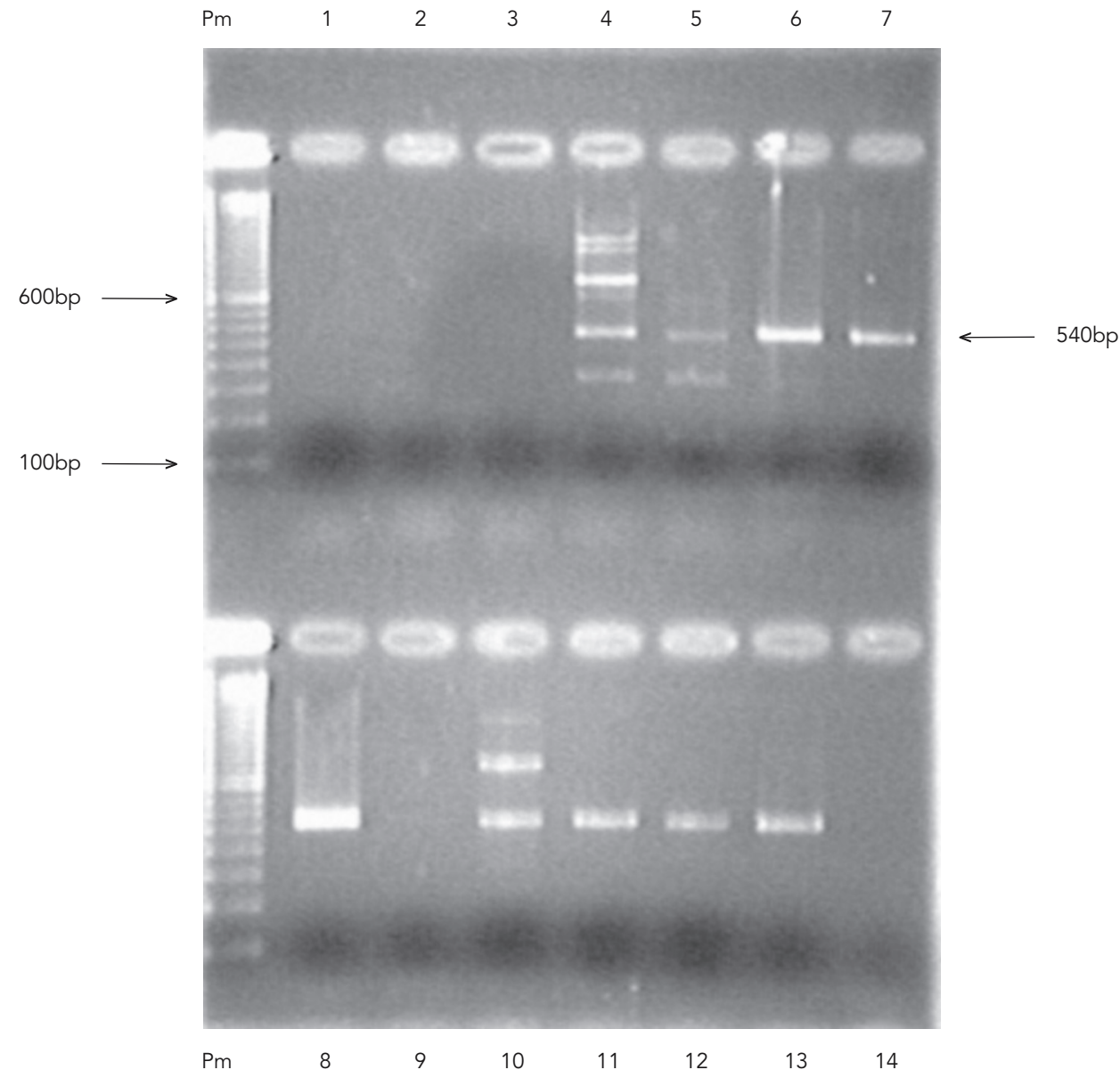

Gel de agarose 1,5\%:

PM 100 bp - 1: pool de 10 conteúdos intestinais + 10 leishmânias; 2: + 20; 4: + 40; 4-5: pool de 10 flebotomíneos íntegros + 10 leishmânias; 6: + 20 leishmânias; 7: + 40 leishmânias; 8: L. (L.) amazonensis; 9: branco; 10: 10 flebotomíneos + leishmânias (106); 11-12: flebotomíneo com 100 e 50 leishmânias; 13: L. (L.) amazonensis; 14: branco.

almerioi e 26 N. intermedia. Foi possível detectar, por PCR, infecção em um espécime de $N$. intermedia (dados não mostrados).

Todas as 14 fêmeas de Lu. longipalpis alimentadas no hamster infectado com $L$. (L.) chagasi apresentaram-se negativas na amplificação por PCR. Esse fato foi corroborado na dissecção, na qual não foi detectada a presença de flagelados em nenhum dos flebotomíneos alimentados em hamster.

\section{Alimentados artificialmente}

Na alimentação artificial, os iniciadores S4/S12 (DNAr) detectaram infecção mínima em 89\% dos insetos alimentados com promastigotas (Figura 2). Para a confirmação da infecção, $7 \%$ dos insetos foram dissecados ao microscópio, apresentando $75 \%$ deles a presença de flagelados em seu tubo digestivo.

\section{Discussão}

A correta identificação das espécies de leishmânias que ocorrem em determinadas áreas endêmicas é de suma importância na adoção de medidas de controle, assim como nas condutas terapêuticas. O processo de armazenamento de insetos para o diagnóstico da infecção natural por Leishmania em flebotomíneos utilizando 


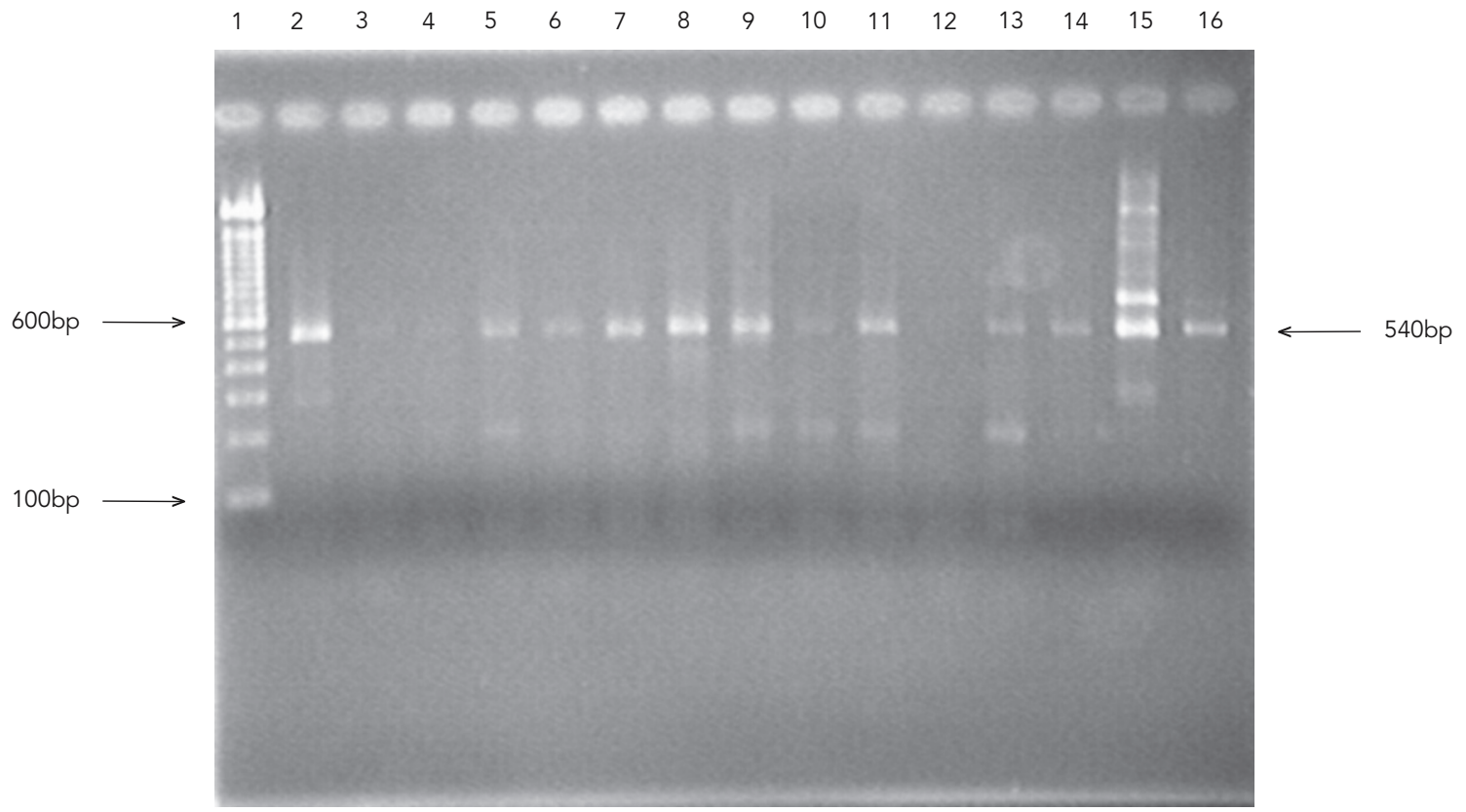

Gel de agarose 1,5\%:

1: PM 100 bp; 2-11 e 13-15: flebotomíneos; 12: branco; 16: L. (L.) amazonensis.

metodologias moleculares, constitui-se em importantes passos prévios a serem sugeridos aos entomologistas de modo a tornar essa ferramenta mais sensível e específica. Assim, com o presente estudo propôs-se a padronizar algumas etapas de conservação desses insetos pós-capturados, adequar um protocolo de extração de DNA para esses insetos na tentativa de amplificar as seqüências específicas de Leishmania.

A facilidade de transporte das amostras com preservação adequada do DNA de um local menos apropriado para outro melhor equipado, mantendo sua integridade por longos períodos, é um dos itens importantes a ser considerado. Para tanto, devem ser avaliadas temperaturas de transporte e condições de conservação (seco ou conservado em algum tipo de reagente). Não esquecendo que certas substâncias utilizadas para a conservação de DNA são quimicamente instáveis, não mantendo a integridade da amostra por muito tempo, sendo a mesma perdida progressivamente. Em nossos experimentos, duas formas de conservação foram avaliadas: (1) em isopropanol, à temperatura ambiente; (2) se$\cos$ a $4^{\circ} \mathrm{C}$. Alguns insetos capturados em campo e conservados em etanol $70 \%$ também foram testados 12 .

Os três métodos de armazenamento (incluindo as amostras conservadas em etanol 70\%) mostraram-se eficientes na preservação do DNA das leishmânias. Assim, considerando que o armazenamento das amostras em isopropanol é mais prático que a refrigeração e mais seguro que o etanol 70\%, o mesmo é sugerido para estudos de campo. Resultados similares foram observados por Cabrera et al. 7, que adotaram para seus experimentos o uso de etanol em temperatura ambiente.

Como os insetos possuem em seus tecidos, inibidores que podem diminuir a eficiência da reação de PCR, majoritariamente em seu exoesqueleto, cabeça e tórax 13,14, em nossos experimentos utilizamos dois tipos diferentes de amostras de flebotomíneos para a avaliação dos métodos de extração de DNA. Um lote continha o tubo digestivo do flebotomíneo retirado por centrifugação, e no outro, insetos inteiros.

O protocolo que incluiu leishmânias ao conteúdo intestinal não apresentou resultados satisfatórios, tendo sido notada a diminuição da sen- 
sibilidade da técnica de PCR e o aparecimento de várias bandas inespecíficas, talvez por prováveis quebras no DNA a ser amplificado. Atribuímos esse fato a uma falha na técnica, pois as formas promastigotas foram adicionadas após a retirada do tubo digestivo, que, por ter sido retirado por centrifugação, pode ter se rompido durante o processo, liberando enzimas digestivas. Estas talvez tenham degradado os parasitas, resultando em quebra de DNA e conseqüente baixa de sensibilidade da reação. Pela dificuldade e dispêndio de tempo na retirada do tubo digestivo, deduziuse que a extração do DNA poderia funcionar com sucesso se testada com flebotomíneos infectados e inteiros. Para isso, comparou-se o DNA extraído dos flebotomíneos inteiros com o do seu tubo digestivo.

Com relação aos protocolos de extração de DNA testados neste trabalho (fenol/clorofórmio/ álcool isoamílico e Triton X100/DTT), os melhores resultados foram aqueles obtidos a partir do método que incluiu Triton X100 e DTT 11. Já o protocolo que inclui passagens em fenol/clorofórmio/álcool isoamílico, não apresentou boa sensibilidade gerando bandas inespecíficas 15 .

Resultados similares foram obtidos por Arez et al. 16 em seus experimentos com identificação de Plasmodium em mosquitos do gênero Anopheles dissecados (conteúdo intestinal, cabeça e tórax) ou inteiros. Esses autores verificaram inibição da reação de PCR pela presença dos inibidores nos tecidos dos insetos, e esta foi particularmente marcada quando se utilizou o protocolo que inclui passagens de fenol/clorofórmio/álcool isoamílico em insetos inteiros. Essa inibição foi quase toda minimizada quando utilizaram a extração de DNA com os métodos de Triton X100 $1 \%$ e DTT ou Chelex, mesmo utilizando-se os insetos inteiros, evitando a necessidade de dissecálos para esta finalidade.

Aransay et al. 17 mencionam que amostras de flebotomíneos com repasto sangüíneo não necessitam de manipulações extras e que a extração de DNA sem passagens com fenol/clorofórmio/álcool isoamílico elimina qualquer inibidor que possa afetar a atividade enzimática do DNA polimerase.

Independente da presença de inibidores nos tecidos, a perda de DNA durante as lavagens com fenol/clorofórmio/álcool isoamílico é indiscutível e a mínima quantidade de DNA perdido durante o processo de extração em insetos pode gerar resultados falsos negativos.

A avaliação geral da reação de PCR com DNA extraído pelo protocolo Triton X100 e DTT, demonstrou ser esta capaz de identificar um parasita por flebotomíneo, resultados estes que estão de acordo com De Bruijn \& Barker 18, em que a presença de um parasita por inseto é suficiente para amplificar seqüências de kDNA (DNA de cinetoplasto). Entretanto, essa sensibilidade pode variar de acordo com os iniciadores e quando espécimes, capturados em campo, são utilizados.

As taxas de infecção dos insetos, alimentados em animais, foram relativamente baixas. Esse resultado é devido ao crescimento dos parasitas nos vertebrados, que é muito lento. Sendo assim, necessita-se de meses para que um número suficiente de amastigotas seja capaz de infectar os flebotomíneos durante seu repasto sangüíneo 9 . Esse fato explica a única infecção detectada pela amplificação de DNA ribossômico nos flebotomíneos alimentados em camundongo infectado com $L$. (L.) amazonensis e pela total falta de detecção nos alimentados com $L$. (L.) chagasi, onde a infecção está concentrada nos órgãos.

$\mathrm{O}$ alimentador artificial demonstrou ser uma alternativa simples e rápida para a infecção de flebotomíneos com Leishmania spp. Provavelmente, isso se explique pela utilização no experimento de formas promastigotas, melhor adaptadas ao ambiente encontrado dentro do tubo digestivo do inseto.

A correta identificação das espécies de flebotomíneos vetores que ocorrem em uma área endêmica de Leishmaniose, bem como as taxas de infecção natural das diferentes espécies de Leishmania, auxiliam na compreensão da epidemiologia da doença e também na adoção de medidas de prevenção e controle desta parasitose 6 .

Taxas de infecção por PCR superiores às da dissecção foram descritas por outros autores. Em área endêmica do Estado da Bahia detectou-se taxa mínima de infecção de até $1,5 \%$ por $L$. $(V$.) braziliensis 19; em ambiente florestal de Mato Grosso do Sul, relata-se para N. whitmani taxa de infecção por flagelados de $0,16 \% 20$, enquanto que a pesquisa realizada no peridomicílio, em localidades onde se notificou casos recentes de leishmaniose cutânea, demonstrou taxa de infectividade por flagelados de $0,52 \% 21$.

A diferenciação entre presença de flagelados e espécies de leishmânias pode auxiliar no controle de seus vetores. Em estudo de campo, realizado na Venezuela, Rodriguez et al. 22 detectaram infecção por flagelados em $2,2 \%$ dos flebotomíneos pertencentes às espécies que na classificação de Galati 9 são denominadas de Micropygomyia cayennensis, Micropygomyia trinidadensis, Psychodopygus panamensis e Lu. gomezi, entretanto, somente as espécies Ps. panamensis e Lu. gomezi apresentaram, no PCR, a taxa de $7,7 \%$ de infecção para $L$. (V.) braziliensis, sendo possível confirmar o papel destas duas espécies na transmissão do parasita nessa região da Venezuela. 
A sensibilidade e especificidade da técnica de PCR pôde ser observada em estudos realizados em áreas da Grécia com casos de leishmaniose visceral. Esse método foi capaz de detectar menos de três parasitas por inseto e identificar $5,4 \%$ de infecção por leishmânias em um total de 645 flebotomíneos de diversas espécies capturadas nessas regiões 17. Em um foco de leishmaniose cutânea no Irã, por meio de PCR, verificou-se que $32,7 \%$ dos espécimens de Phlebotomus papatasi capturados estavam positivos para $L$. (L.) major 23 .

Como já foi observado, além da alta sensibilidade da técnica, a especificidade do PCR quando se utiliza iniciadores que amplificam seqüências específicas do parasita, auxilia muito nos estudos de incriminação vetorial. Mukherjee et al. 24, na Índia, identificaram infecção para $L$. (L.) donova$n i$ em $46 \%$ de insetos das espécies $P h$. argentipes, Ph. papatasi e Sergentomyia babu, como também demonstraram a viabilidade dos parasitas em todas as espécies de flebotomíneos por meio da presença de RNA mensageiro de leishmânias metabolicamente ativas. Em um estudo nos Andes, Peru, por dissecção foram detectadas formas flageladas em $0,49 \%$ das fêmeas de $L u$. ayacuchensis e 1,42\% das de Lu. noguchii, no entanto, por PCR, apenas foi demonstrada a presença de L. (Viannia) sp. nas fêmeas de Lu. ayacuchensis, demonstrando assim que esta espécie é a envolvida na transmissão de leishmaniose nessas áreas 25. Já na região andina do Equador, esse vetor foi identificado infectado por $L$. (L.) mexicana com taxa de infecção de 3,3\% por meio de técnicas moleculares 26 .

Em suma, após padronização da conservação e extração de DNA de flebotomíneos, verificouse, neste estudo, que a técnica de PCR foi capaz de identificar infecção por Leishmania em flebotomíneos experimentalmente infectados. Ainda que preliminar este estudo, acreditamos poder colaborar para estudos epidemiológicos na investigação de infecção natural por Leishmania em flebotomíneos, possibilitando a identificação específica dos parasitas envolvidos.

\section{Resumo}

A correta identificação dos agentes etiológicos em insetos vetores é de crucial importância aos estudos epidemiológicos. A pesquisa de flagelado nesses vetores, pela dissecção de seu trato digestivo, observação microscópica do seu conteúdo ou por isolamento dos parasitas provenientes de insetos em meios de cultura, tem-se mostrado operacionalmente inadequada e com baixa especificidade do diagnóstico, pois fêmeas de flebotomíneos também podem albergar outros flagelados como Trypanosoma $e$ Endotrypanum. Acreditamos que por sua eficiência e especificidade, a amplificação de seqüências-alvo do DNA da Leishmania, por meio da reação em cadeia de polimerase, pode ser aplicada na investigação de sua presença em flebotomíneos, desde que estes estejam devidamente acondicionados e o DNA do parasita extraído a partir de metodologia adequada. Este trabalho descreve metodologias utilizadas na padronização da conservação dos espécimes de flebotomíneos e extração do DNA da Leishmania como uma alternativa mais prática que os métodos tradicionais.

Psychodidae; Leishmania; Reação em Cadeia da Polimerase

\section{Colaboradores}

Todos os autores contribuíram de igual maneira na elaboração deste artigo.

\section{Agradecimentos}

Auxilio financeiro do Laboratório de Investigação Médica (LIM-49), Faculdade de Medicina, Universidade de São Paulo, do Conselho Nacional de Desenvolvimento Científico e Tecnológico (CNPq), da Coordenação de Aperfeiçoamento de Pessoal de Nível Superior (CAPES) e da Fundação de Amparo à Pesquisa do Estado de São Paulo (FAPESP, 00/06811-0). 


\section{Referências}

1. Bryceson ADM. Leishmaniasis. In: Cook GC, editor. Manson's tropical diseases. 12 th Ed. London: WB Saunders; 1996. p. 1213-45.

2. Forattini OP. Entomologia médica. v. 4. São Paulo: Editora Blucher; 1973.

3. Shaw JJ, Lainson R. Ecology and epidemiology: new world. In: Peters W, Killick-Kendrick R, editors. The leishmaniasis in biology and medicine. v. I. Orlando: Academic Press; 1987. p. 291-363.

4. Silva AC, Gomes AC. Estudo da competência vetorial de Lutzomyia intermedia (Lutz \& Neiva, 1912) para Leishmania (Viannia) braziliensis, Viannia, 1911. Rev Soc Bras Med Trop 2001; 34:187-91.

5. Neves DP. Parasitologia humana. 8a Ed. São Paulo: Editora Atheneu; 1991.

6. Michalsky EM, Fortes-Dias CL, Pimenta PFP, Secundino NFC, Dias ES. Assessment of PCR in the detection of Leishmania spp. in experimentally infected individual phlebotomine sandflies (Diptera: Psychodidae: Phlebotominae). Rev Inst Med Trop São Paulo 2002; 44:255-9.

7. Cabrera OL, Munsterman LE, Cardenas R, Gutierrez R, Ferro C. Definition of appropriate temperature and storage conditions in the detection of Leishmania DNA with PCR in phlebotomine flies. Biomédica (Bogotá) 2002; 22:296-302.

8. Uliana SRB, Nelson K, Beverley SM, Camargo EP, Floeter-Winter LM. Discrimination amongst Leishmania by polymerase chain reaction and hybridization with small subunit ribosomal DNA derived oligonucleotides. J Eukaryot Microbiol 1994; 41:324-30.

9. Galati EAB. Classificação de Phlebotominae. In Rangel EF, Lainson R, organizador. Flebotomíneos do Brasil. Rio de Janeiro: Editora Fiocruz; 2003. p. 23-51.

10. Tesh RB, Modi GB. A simple method for experimental infection of Phlebotomine sand flies with Leishmania. Am J Trop Med Hyg 1984; 33:41-6.

11. Oskam L, Schoone GJ, Kroon CCM, Lujan R, Davies JB. Polymerase chain reaction for detecting Onchocerca volvulus in pools of blackflies. Trop Med Int Health 1996; 4:522-7.

12. Paiva BR. Desenvolvimento e avaliação da reação em cadeia de polimerase (PCR) na determinação da infecção por leishmânias em flebotomíneos vetores (Diptera, Psychodidae) [Dissertação de Mestrado]. São Paulo: Instituto de Ciências Biomédicas, Universidade de São Paulo; 2005.

13. Higgins JA, Azard AF. Use of polymerase chain reaction to detect bacteria in Arthropods: a review. J Med Entomol 1995; 32:213-22.

14. Siridewa K, Karunanayake EH, Chandrasekharan NV. Polymerase chain reaction-based technique for the detection of Wuchereria bancrofti in human blood samples hydrocele fluid, and mosquito vector. Am J Trop Med Hyg 1996; 54:72-6.

15. Paiva BR, Savani ESMM, Galati EAB, Andrade Jr. HF. Comparison of DNA extraction procedures for Leishmania PCR from stored sandflies. Rev Inst Med Trop São Paulo 2003; 45:170.
16. Arez AP, Lopes D, Pinto J, Franco AS, Snounou G, Rosário VE. Plasmodium sp.: optimal protocols for PCR detection of low parasite numbers from mosquito (Anopheles sp.) samples. Exp Parasitol 2000; 94:269-72.

17. Aransay AM, Scoulica E, Tselentis Y. Detection and identification of Leishmania DNA within naturally infected sand flies by seminested PCR on minicircle kinetoplastic DNA. Appl Environ Microbiol 2000; 66:1933-8.

18. De Bruijn MH, Barker DC. Diagnosis of new world leishmaniasis: specific detection of species of the Leishmania braziliensis complex by amplification of kinetoplast DNA. Acta Trop 1992; 52:45-58.

19. Miranda JC, Reis E, Schiefer A, Gonçalves M, Reis MG, Carvalho L, et al. Frequency of infection of Lutzomyia Phlebotomines with Leishmania braziliensis in a Brazilian endemic area as assessed by Pinpoint Capture and Polimerase Chain Reaction. Mem Inst Oswaldo Cruz 2002; 97:185-8.

20. Galati EAB, Nunes VLB, Dorval MEC, Oshiro ET, Cristaldo G, Espindola MA, et al. Estudo dos flebotomíneos (Diptera, Psychodidae), em área de leishmaniose tegumentar, no Estado de Mato Grosso do Sul, Brasil. Rev Saúde Pública 1996; 30:115-28.

21. Ryan L, Vexenat A, Marsden PD, Lainson R, Shaw JJ. The importance of rapid diagnosis of new cases of cutaneous Leishmaniasis in pin-pointing the sandfly vector. Trans R Soc Trop Med Hyg 1990; 84:786.

22. Rodriguez N, Aguilar CM, Barrios MA, Barker DC. Detection of Leishmania (V.) braziliensis in naturally infected individual sandflies by the polymerase chain reaction. Trans R Soc Trop Med Hyg 1999; 93:47-9.

23. Parvizi P, Mauricio I, Aransay AM, Miles MA, Ready PD. First detection of Leishmania major in peridomestic Phlebotomus papatasi from Isfahan province, Iran: comparison of nested PCR of nuclear ITS ribossomal DNA and semi-nested PCR of minicircle kinetoplast DNA. Acta Trop 2005; 93:75-83.

24. Mukherjee S, Hassan MQ, Ghosh A, Ghosh KN, Bhattacharya A, Adhya S. Leishmania DNA in Phlebotomus and Sergentomyia species during a kalazar epidemic. Am J Trop Med Hyg 1997; 57:423-5.

25. Caceres AG, Villaseca P, Dujardin JC, Bañuls AL, Lopez RIM, Arana M, et al. Epidemiology of Andean cutaneous leishmaniasis: incrimination of Lutzomyia ayacuchensis (Diptera: Psychodidae) as a vector of Leishmania in geographically isolated, upland valleys of Peru. Am J Trop Med Hyg 2004; 70:607-12.

26. Kato H, Uezato H, Katakura K, Calvopina M, Marco JD, Barroso PA, et al. Detection and identification of Leishmania species within naturally infected sand flies in the Andean areas of Ecuador by a polymerase chain reaction. Am J Trop Med Hyg 2005; 72:87-93.

Recebido em 04/Jan/2006

Versão final reapresentada em 27/Abr/2006

Aprovado em 09/Mai/2006 